\title{
Cryofibrinogenemia Associated with Sjögren's Syndrome: A case of Successful Treatment with High-dose Corticosteroid
}

\author{
Ken Yoshida, Toru Yokoyama, Yasuhiko Toyokawa, Jun Yasuda, Isamu Kingetsu, \\ Daitaro Kurosaka and Akio Yamada
}

\begin{abstract}
Cryofibrinogenemia (CF) has not been often reported as a complication of various rheumatic diseases. We describe a 44-year-old woman with CF associated with Sjögren's syndrome (SS), who developed digital necrotic ulcerations and purpura of the lower legs. Cryoprecipitate was detected in her plasma, and immunoelectrophoresis showed that the cryoprecipitate was cryofibrinogen. Alprostadil was intravenously administered, but the ulceration was aggravated. Subsequently, administration of high-dose prednisolone (PSL) at 60 $\mathrm{mg} / \mathrm{day}$ was started, and the ulceration remarkably improved. Cryofibrinogen, detected before the administration of high-dose PSL, was negative after PSL. This is the first case presentation of CF associated with SS successfully treated with high-dose corticosteroid.
\end{abstract}

Key words: cryofibrinogenemia, Sjögren's syndrome, corticosteroid, prednisolone, ulceration, purpura

(DOI: 10.2169/internalmedicine.46.6311)

\section{Introduction}

Cryofibrinogen, described by Korst and Kratochvil in 1955 , is an abnormal protein that reversibly precipitates in plasma by cold temperatures $\left(4^{\circ} \mathrm{C}\right)$, and redissolves upon warming to $37^{\circ} \mathrm{C}$ (1). Cryofibrinogen is a cold insoluble complex of fibrin, fibrinogen, and fibrin split products with albumin, cold insoluble globulin, factor VIII, and other plasma proteins (2). Cryofibrinogenemia (CF) is a disorder characterized by cryoprecipitation with a variable clinical presentation. CF itself is often asymptomatic (3); however patients with clinically relevant skin lesions, such as purpura, livedo reticularis, ulceration, or gangrene, have been reported, as well as those with arthritis, and glomerulonephritis (4). CF may be primary or secondary to an underlying disorder including: carcinoma, infection, inflammation, collagen disease, thromboembolic disease, acute myocardial infarction, diabetes mellitus, and hypothyroidism (35). It has been reported that various organ disorders are associated with Sjögren's syndrome (SS), but CF associated with SS is rarely reported. Here, we describe the first report of a case of CF associated with SS whereby treatment with high-dose corticosteroid was successful.

\section{Case Report}

In February 2004, a 44-year-old Japanese woman presented with a digital necrotic ulceration. Since 1980, she has suffered from Raynaud's phenomenon and dry mouth. From 2003, numbness of the bilateral lower legs developed. Two months before admission to our hospital, she started to experience palpable purpura of the lower legs, often induced by exposure to cold, and digital necrotic ulceration of the left fourth finger developed. She was pointed out as having positive antinuclear antibodies at a local hospital. She was suspected of having collagen disease, and PSL at $20 \mathrm{mg} / \mathrm{day}$ was started. In spite of PSL administration, the digital necrotic ulceration was aggravated, and she was admitted to our hospital in February 2004.

Examination on admission revealed a weight of $62 \mathrm{~kg}$, blood pressure $136 / 88 \mathrm{mmHg}$, pulse $68 / \mathrm{min}$, and temperature $36.7^{\circ} \mathrm{C}$. No abnormal thoracic or abdominal findings were observed. The digital necrotic ulceration was observed 


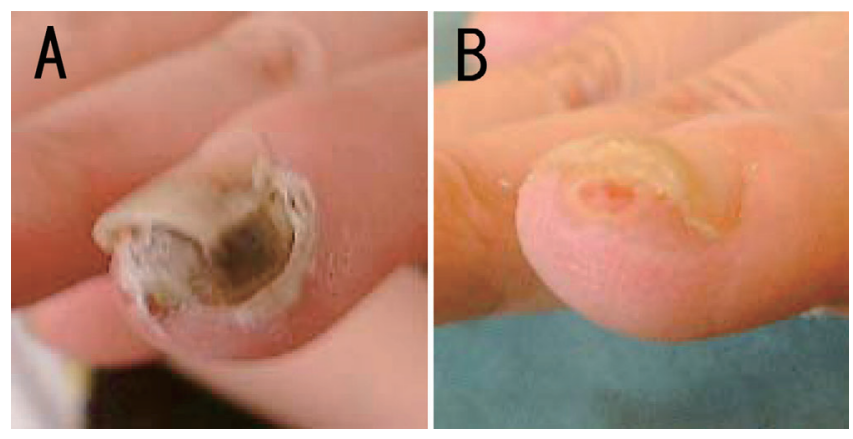

Figure 1. The digital necrotic ulceration: A, pretreatment of high-dose PSL; B, post-treatment of high-dose PSL.

on the left fourth finger (Fig. 1A) and multiple palpable purpura on the lower legs. Neurological examinations revealed hypalgesia and thermohypoesthesia on the sural nerve area of her bilateral lower legs. Laboratory studies were notable for the following values: white blood cell count of $6,200 / \mu 1$ with normal differentiation, hemoglobin $12.8 \mathrm{~g} / \mathrm{dl}$, platelet count $198 \times 10^{3} / \mu \mathrm{l}$, ESR $35 \mathrm{~mm} / \mathrm{h}$ (normal: $3-19$ ), PT $100 \%$ (normal: 70-100), APTT 36.4 seconds (normal: 29.0-41.0), fibrinogen $297 \mathrm{mg} / \mathrm{dl}$ (normal: 150-400), $\alpha 1$ antitrypsin 176 $\mathrm{mg} / \mathrm{dl}$ (normal: 94-150), $\alpha 2$ macrogloblin $252 \mathrm{mg} / \mathrm{dl}$ (normal: 130-250), and C-reactive protein (CRP) $0.07 \mathrm{mg} / \mathrm{dl}$ (normal: <0.3). There was no abnormality in serum transaminase, lactate dehydrogenase, creatinine, urea nitrogen, and on urinalysis. Immunological studies showed the following: a positive rheumatoid factor of $126.9 \mathrm{IU} / \mathrm{ml}$, positive anti-nuclear antibodies with a titer of $1: 640$, positive antiSS-A/Ro of $>500 \mathrm{U} / \mathrm{ml}$, anti-SS-B/La of $21.3 \mathrm{U} / \mathrm{ml}$ antibodies, and anticentromere antibody of $229.2 \mathrm{U} / \mathrm{ml}$, negative or within normal limit $\mathrm{C}_{3}$ and $\mathrm{C}_{4}$ complement levels, immunoglobulin, anti-ds-DNA, anti-RNP, anti-Sm, anti-scl-70, anticardiolipin $\beta 2$ glycoprotein I, myeloperoxidase-antineutrophil cytoplasmic antibody (MPO-ANCA), and proteinase3 (PR3)-ANCA. HBs antigen and HCV antibody were negative. The chewing gum test identified reduced salivation (8 $\mathrm{ml} / 10 \mathrm{~min}$ ) from the salivary glands. ${ }^{99 \mathrm{~m}} \mathrm{Tc}^{-\mathrm{O}_{4}}$ scintigraphy of the salivary glands showed a lower uptake of radioisotope in the parotid and submandibular glands. Lip biopsy demonstrated significant lymphoid cell infiltration in the minor salivary gland. She was diagnosed as having primary SS. A skin biopsy from a purpura lesion of the right lower leg was performed. In a small vessel of the upper dermis, an inflammation infiltrate consisting of neutrophils, lymphocytes, and macrophages was observed as well as nuclear dust and extravasation of erythrocytes. Immunofluorescent studies revealed $\mathrm{C}_{3}$ located in the vascular walls, but no immunoglobulin deposits were found. The findings were compatible with the diagnosis of leukocytoclastic vasculitis $(6,11)$. The combination of her clinical symptoms and the finding on skin biopsy indicated a possibility of cryoglobulinemia (CG) or CF. Investigation for cryofibrinogen and cryoglobulin was performed using $14 \mathrm{ml}$ of normal healthy donor ethylenediaminetetraacetic acid (EDTA) blood and the patient's EDTA blood centrifuged for 15 minutes at $37^{\circ} \mathrm{C}$ immediately fol-
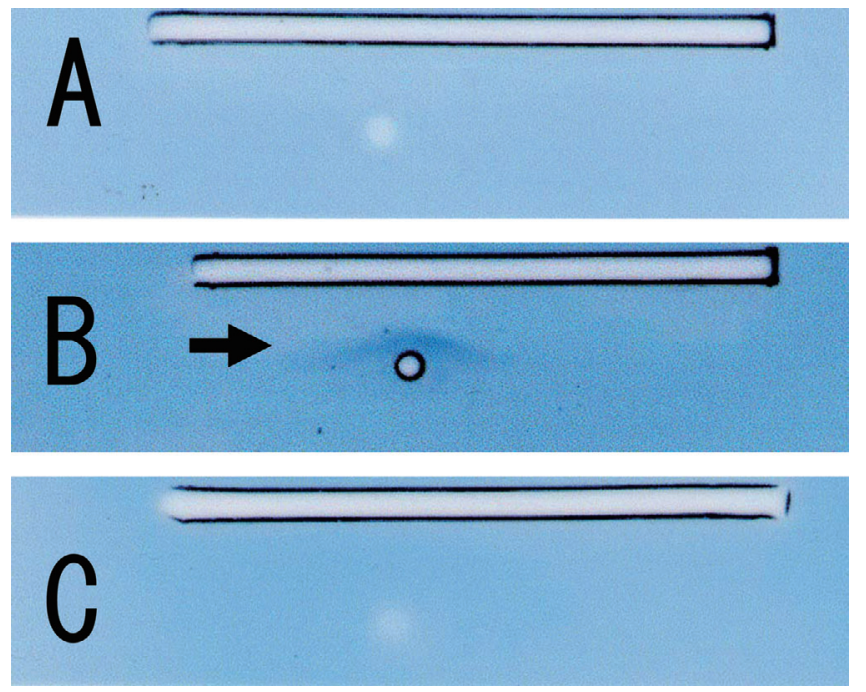

Figure 2. Immunoelectrophoresis of cryoprecipitate solution: A, normal healthy donor; $B$, patient before treatment of high-dose PSL; C, patient after treatment of high-dose PSL; arrow, a dense band with fibrinogen.

lowing sampling. To each plasma sample an antiseptic ( $0.01 \%$ sodium azide) was added and incubated for 7 days at $4{ }^{\circ} \mathrm{C}$. Centrifugation $\left(15\right.$ minutes at $\left.2,000 \mathrm{~g}, 4^{\circ} \mathrm{C}\right)$ resulted in a visible precipitate in the patient's sample. The cryoprecipitate was washed three times with cold $0.9 \%$ sodium chloride solution. It was then dissolved in the solution at 37 ${ }^{\circ} \mathrm{C}$ after 15 minutes $(4,6,7)$. To analyze the precipitated protein, immunoelectrophoresis was performed and showed only a fibrinogen arc in the patient's sample (Fig. 2B), and not in the normal healthy donor sample (Fig. 2A). An immunoglobulin arc was not clearly detected by immunoelectrophoresis in the patient's sample. Based on these results, the diagnosis of CF was made.

PSL (15 mg/day), which was administered in a local hospital, was tapered and discontinued after the admission. She was treated with intravenous alprostadil $(10 \mu \mathrm{g} / \mathrm{day})$ and oral aspirin $(100 \mathrm{mg} /$ day $)$. The digital necrotic ulceration of the left fourth finger became aggravated despite these treatments, and a digital necrotic ulceration of the right first finger also developed. Therefore, treatment with high-dose PSL (60 mg/day) was started. After starting high-dose PSL treatment, the ulcerations gradually improved, and thus the PSL dose was tapered to $40 \mathrm{mg}$ daily. At that time, plasma cryofibrinogen was undetectable (Fig. 2C). $\alpha 1$ antitrypsin and $\alpha 2$ macrogloblin, which increase in $\mathrm{CF}(5,6)$, also normalized after treatment with high-dose PSL. Because there was marked improvement of the ulcerations at 6 weeks after starting high-dose PSL (Fig. 1B), alprostadil was discontinued. The patient was discharged in May 2004, in good general condition on PSL $40 \mathrm{mg}$ daily. Although the PSL dose was gradually tapered to $8 \mathrm{mg}$ daily, the patient was well without recurrence of the ulcerations in October 2006. 
Table 1. The Present Case and Previously Reported Cases of Cryofibrinogenemia Secondary to Rheumatic Disease

\begin{tabular}{|c|c|c|c|c|c|c|c|}
\hline No & References & Age & Sex & Diagnosis & Symptoms & Treatment & Outcome \\
\hline 1 & 4 & 37 & $\mathrm{M}$ & Behçet's disease & Heamoptysis & Prednisone, Azathioprine & Remission \\
\hline 2 & 4 & 67 & M & Periarteritis nodosa & Neuromyositis & Prednisone & Remission \\
\hline 3 & 4 & 50 & $\mathrm{~F}$ & Periarteritis nodosa & Purpura, livedo & $\begin{array}{l}\text { Colchicine, Aspirin, } \\
\text { IFN- } \alpha\end{array}$ & $\begin{array}{l}\text { Recurrence of } \\
\text { skin lesions }\end{array}$ \\
\hline 4 & 8 & 21 & M & Polyarteritis nodosa & Melaena & Operation & Remission \\
\hline 5 & 9 & 77 & $\mathrm{~F}$ & Polyarteritis nodosa & $\begin{array}{l}\text { Livedo reticularis, } \\
\text { digital gangrene }\end{array}$ & $\begin{array}{l}\text { Methylprednisolone pulse } \\
\text { PSL } 40 \mathrm{mg}\end{array}$ & Remission \\
\hline 6 & 4 & 39 & F & Polymyositis & Muscle weakness and pain & Prednisone & Improvement \\
\hline 7 & 4 & 76 & $\mathrm{~F}$ & Polymyositis & Fever, muscle weakness & Prednisone & Died (Septic shock) \\
\hline 8 & 4 & 57 & $\mathrm{~F}$ & Polymyositis & Muscle weakness & Prednisone & Remission \\
\hline 9 & 4 & 34 & M & SLE & Kidney involvment & $\begin{array}{l}\text { Cyclophosphamide, } \\
\text { Prednisone, Aspirin }\end{array}$ & Remission \\
\hline 10 & 4 & 62 & $\mathrm{~F}$ & Scleroderma & $\begin{array}{l}\text { Raynaud's phenomenon, } \\
\text { skin necrotic ulcerations }\end{array}$ & $\begin{array}{l}\text { Prostacyclin, } \\
\text { Calcium blocker }\end{array}$ & $\begin{array}{l}\text { Recurrence of } \\
\text { skin lesions }\end{array}$ \\
\hline 11 & 10 & 49 & M & Systemic sclerosis & Digital gangrene & $\begin{array}{l}\text { Heparin, Dextran 40, } \\
\text { Prostaglandin E1 }\end{array}$ & Died \\
\hline 12 & 11 & 19 & M & Henoch-Schönlein purpura & $\begin{array}{c}\text { Petechiae, purpuric papules, } \\
\text { abdominal pain }\end{array}$ & Methylprednisolone $60 \mathrm{mg}$ & Remission \\
\hline 13 & 12 & 29 & M & Henoch-Schönlein purpura & $\begin{array}{l}\text { Necrotizing skin, } \\
\text { purpura, arthralgia }\end{array}$ & Stanasol 5mg, PSL $7.5 \mathrm{mg}$ & Amputation of fingers \\
\hline 14 & 13 & 64 & $\mathrm{~F}$ & Henoch-Schönlein purpura & $\begin{array}{l}\text { Muscle weakness and pain, } \\
\text { necrotic lesions, arthralgia }\end{array}$ & $\begin{array}{l}\text { Cyclophosphamide }(1 \mathrm{mg} / \mathrm{kg}) \text {, } \\
\text { PSL } 75 \mathrm{mg} \text {, Plasmapheresis }\end{array}$ & Remission \\
\hline 15 & 4 & 69 & $\mathrm{~F}$ & Sjögren's disease & $\begin{array}{l}\text { Necrotic lesions, } \\
\text { purpuric lesions }\end{array}$ & Prednisone & Died (Septic shock) \\
\hline 16 & our case & 44 & $\mathrm{~F}$ & Sjögren's disease & $\begin{array}{c}\text { Necrotic ulcerations, } \\
\text { purpura lesions }\end{array}$ & $\begin{array}{l}\text { Alprostadil, Aspirin, } \\
\text { PSL 60mg }\end{array}$ & Remission \\
\hline
\end{tabular}

\section{Discussion}

CF may be primary or secondary to an underlying disorder including: carcinoma, infection, inflammation, collagen disease, thromboembolic disease, acute myocardial infarction, diabetes mellitus, and hypothyroidism (3-5). Fifteen cases of CF secondary to rheumatic diseases, other than the present case, have been previously described (4, 8-13) (Table 1). Among these cases, CF associated with SS was rare. The age of patients varied from young to aged (range: 21-77 years), and the male/female ratio of patients was $7: 9$. Clinical symptoms that occurred due to $\mathrm{CF}$ tended to differ according to the underlying disease. Skin necrotic ulcerations, which also developed in the present case, were frequently observed in CF secondary to SS, scleroderma, Henoch-Schonlein purpura, and polyarteritis nodosa. The most commonly used pharmaceutical treatments include stanozolol, streptokinase, and steroids in CF (4, 6, 14-17). Prednisone or PSL was frequently administered to CF secondary to rheumatic disease. CF secondary to rheumatic disease did not recur as much as primary $\mathrm{CF}$, and improved easily via treatment with corticosteroid compared with primary CF (Table 1). But three patients died. Among these three patients, two patients died of infection, and one patient of ischemia. CF secondary to SS except for the present case comprised only one case with both $\mathrm{CG}$ and $\mathrm{CF}$ and a death case. Because in the present case, CF was secondary to SS, rheumatic disease and the digital necrotic ulcerations aggravated after discontinuing PSL, we chose treatment with high-dose PSL. The ulcerations which did not improve by administration of alprostadil were ameliorated by treatment with high-dose PSL. Therefore, we thought that high-dose PSL was effective for the ulcerations. Amdo and Welker of- fered that steroids should be used as needed for the treatment of an underlying inflammatory condition (e.g., collagen vascular disease), which can help in the control of $\mathrm{CF}$ (6). In CF secondary to SS, the present case constitutes the first case of successful treatment, and is the only clinical course reported in detail.

In the present case, since the findings of positive anti-SSA/Ro, anti-SS-B/La antibodies, hyposalivation, and sialadenitis fulfilled the European diagnostic criteria of primary SS (18), diagnosis of CF secondary to SS was established after the detection of cryofibrinogen. Although $\mathrm{CF}$ may cause skin ulcerations generally $(4,6)$, Burger's disease, arteriosclerosis obliterans, systemic sclerosis, anti-phospholipid syndrome, and vasculitis syndrome were considered possibilities as differential diagnoses of causes of the digital necrotic ulcerations. But sclerodactylia, lung fibrosis, and impaired mobility of the esophagus were not observed, and a contrast-enhanced CT scan of the lower extremities and doppler ultrasonography of the upper extremities revealed no stricture of the arteries and deep venous thrombosis. Moreover, CRP was negative throughout the course from the preadministration of PSL, and MPO-ANCA and anticardiolipin $\beta 2$ glycoprotein I antibody were also negative. Therefore, those diseases were thought to be unlikely in the absence of positive findings for these parameters. But we were not able to exclude local vasculitis without CRP elevation, because we did not perform a skin biopsy of the ulceration site in fear of delaying the recovery of the ulceration. CF may cause skin ulcerations, Raynaud's phenomenon, peripheral neuropathy, purpura, and leukocytoclastic vasculitis (4), and cutaneous vasculitis in primary SS also these clinical symptoms (19). Therefore, in the present case, the ulcerations were considered to be caused by $\mathrm{CF}$ and/or cutaneous vasculitis. CF itself is often asymptomatic, but in about $11 \%$ 
CF is symptomatic (3). There is no correlation between the levels of $\mathrm{CF}$ and either disease intensity or cold sensitivity (4). Most symptomatic patients present either essential or collagen disease-related CF (3). Patients with symptomatic $\mathrm{CF}$ present with temporal association between exposure to cold and the onset of symptoms (6). Patients with isolated $\mathrm{CF}$ suffered more frequently from recurrent and necrotic skin lesion (mainly triggered by cold exposure) than patients with both CF and CG (4). CF may cause thrombotic occulusion of the small vessels, especially in the skin, via either reflex vasospasm, vascular stasis, and/or hyperviscosity (6). Typical skin biopsy findings in CF are cryofibrinogen plugging vessels, leukocytoclastic vasculitis, or dermal necrosis (6). In the present case, purpura lesion histopathological findings were leukocytoclastic vasculitis often induced by exposure to cold, and that the digital necrotic ulceration appeared at the same time. Although vascular occlusion and subsequent ischemic tissue damage are not rare in vasculitis (e.g., polyarteritis), cold-induced symptoms are not generally perceived in vasculitis (9). Thus, we thought that CF was associated with one of the causes of the ulcerations.

We detected the cryoprecipitate in the patient's EDTA plasma and cryofibrinogen from the cryoprecipitate by immunoelectrophoresis. We thought that not only the detection of cryoprecipitate but also cryofibrinogen by immunoelectrophoresis should be performed to diagnose CF correctly, because cryoprotein is likely to consist of some kinds of protein (2). By using this method, cryofibrinogen was detected before treatment with high-dose PSL, and not after. But the plasma level of fibrinogen hardly changed before and after treatment with high-dose PSL. These results suggest that any factors leading to the formation of cryofibrinogen can be suppressed by high-dose PSL administration. It is true that cryofibrinogen was not detected after the administration of high-dose PSL, which may be related to the improvement of the ulcerations.

When rheumatic diseases are accompanied by coldinduced skin ulceration, it is necessary to consider the possibility that the ulceration is caused by CF. In such a case, high-dose corticosteroid therapy should be considered.

The authors would like to thank Dr. Kensuke Joh (Division of Immunopathology, Clinical Research Center, Chiba-East National Hospital) for providing helpful comments.

\section{References}

1. Korst DR, Kratochvil CH. Cryofibrinogen in a case of lung neoplasm associated with thrombophlebitis migrans. Blood 10: 945953, 1955.

2. Stathakis NE, Karamanolis D, Koukoulis G, Tsianos E. Characterization of cryofibrinogen isolated from patients plasma. Haemostasis 10: 195-202, 1981.

3. Zlotnick A, Shahin W, Rachmilewitz EA. Studies in cryofibrinogenemia. Acta Haematol 42: 8-17, 1969.

4. Blain H, Cacoub P, Musset L, et al. Cryofibrinogenaemia: a study of 49 patients. Clin Exp Immunol 120: 253-260, 2000.

5. Smith SB, Arkin C. Cryofibrinogenemia: incidence, clinical correlations, and a review of the literature. Am J Clin Pathol 58: 524530, 1972.

6. Amdo TD, Welker JA. An approach to the diagnosis and treatment of cryofibrinogenemia. Am J Med 116: 332-337, 2004.

7. Kalbfleisch JM, Bird RM. Cryofibrinogenemia. N Engl J Med 263: 881-886, 1960.

8. Meehan SE, Coghill SB, Cuschieri A. A case of childhood polyarteritis nodosa associated with cryofibrinogenaemia presenting in adulthood with massive gastrointestinal bleeding. Scott Med J 28: 302-305, 1983.

9. Shimbo J, Miwa A, Aoki K. Cryofibrinogenemia associated with polyartheritis nodosa. Clin Rheumatol 25: 562-563, 2006.

10. Barrett MC, Prendiville JS, Pardy BJ, Cream JJ. Cryofibrinogenaemia and acute gangrene in systemic sclerosis. Postgrad Med J 62: 935-936, 1986.

11. Cwazka WF, Sprenger JD, Naguwa SN, Birnberg FA. Cryofibrinogenemia in Henoch-Schönlein purpura: report of a case. Arch In- tern Med 139: 592-593, 1979.

12. Gerke P, Kruger S, Steinhoff J. Henoch-Schönlein purpura, cryofibrinogenaemia, and peripheral gangrene. Nephrol Dial Transplant 14: 1746-1749, 1999.

13. Alexopoulos E, Kirmizis D, Visvardis G, et al. Cryofibrinogenemia due to Henoch-Schönlein purpura in a patient on peritoneal dialysis. Perit Dial Int 23: 85-87, 2003.

14. Falanga V, Kirsner RS, Eaglstein WH, Katz MH, Kerdel FA. Stanozolol in treatment of leg ulcers due to cryofibrinogenaemia. Lancet 338: 347-348, 1991.

15. Kirsner RS, Eaglstein WH, Katz MH, Kerdel FA, Falanga V. Stanozolol causes rapid pain relief and healing of cutaneous ulcers caused by cryofibrinogenemia. J Am Acad Dermatol 28: 71-74, 1993.

16. Rubegni P, Flori ML, Fimiani M, Andreassi L. A case of cryofibrinogenaemia responsive to stanozolol. Br J Haematol 93: 217219, 1996.

17. Revenga F, Aguilar C, Gonzalez R, Paricio JF, Sanz P, Santos I. Cryofibrinogenaemia with a good response to stanozolol. Clin Exp Dermatol 25: 621-623, 2000.

18. Vitali C, Bombardieri S, Moutsopoulos HM, et al. Preliminary criteria for the classification of Sjögren's syndrome. Results of a prospective concerted action supported by the European Community. Arthritis Rheum 36: 340-347, 1993.

19. Ramos-Casals M, Anaya JM, Garcia-Carrasco M, et al. Cutaneous vasculitis in primary Sjögren syndrome: classification and clinical significance of 52 patients. Medicine (Baltimore) 83: 96-106, 2004.

(C) 2007 The Japanese Society of Internal Medicine

http://www.naika.or.jp/imindex.html 